\title{
Neuroendocrine Responses to Transvascular Autonomic Modulation: A Modified Balloon Angioplasty in Multiple Sclerosis Patients
}

\author{
Authors \\ M. Arata, Z. Sternberg \\ Affiliation \\ Autonomic Specialists, 4501 Birch Street, Newport Beach, USA
}

\author{
Key words \\ - autonomic function \\ - balloon angioplasty \\ - blood pressure \\ - CCSVI \\ - HPA axis \\ - heart rate variability
}

received 10.01 .2015

accepted 04.02.2015

\section{Bibliography}

DOI http://dx.doi.org/

10.1055/s-0035-1547235

Published online:

March 19, 2015

Horm Metab Res 2016;

48: 123-129

(c) Georg Thieme Verlag KG

Stuttgart · New York

ISSN 0018-5043

\section{Correspondence}

\section{Arata, MD}

Autonomic Specialists

4501 Birch Street

Newport Beach

CA 92660

USA

Tel.: + 1/949/395 4304

Fax: + 1/949/223 4702

endovasc@gmail.com

\section{Abstract}

$\nabla$

Balloon angioplasty (BA) is a treatment modality to correct vascular lesions in multiple sclerosis (MS) patients, who present with chronic cerebrospinal venous insufficiency (CCSVI). We hypothesized that BA clinical benefits stems in part from improvement in cardiovascular autonomic nervous system (ANS) function. We adopted the Transvascular Autonomic Modulation (TVAM), as a modified BA technique, with the objective of further enhancing ANS functional activities. TVAM involved dilation of multiple vascular beds, including IJVs, azygos and renal veins, and application of manual compression. Since the ANS regulates the function of the hypothalamus pituitary (HPA) axis, we examined TVAM effects on HPA axis in MS patients, and determined the relationship between ANS function and HPA activity. The adrenocorticotropic hormone (ACTH) and cortisol serum levels, systolic and diastolic blood pressure (BP), and heart rate variability (HRV) parameters were measured before and

\section{Abbreviations}

$\nabla$

ACTH Adrenocorticotropic hormone

ANS Autonomic nervous system

BA Balloon angioplasty

CCSVI Chronic cerebrospinal venous insufficiency

HPA Hypothalamus-pituitary-adrenal

MS Multiple sclerosis

\section{Introduction}

\section{$\nabla$}

The recently set forth vascular theory of Chronic CerebroSpinal Venous Insufficiency (CCSVI) has been described as hemodynamic disturbances of the CNS venous drainage, resulting from
$24 \mathrm{~h}$ after TVAM procedure in 72 MS patients. Baseline ACTH and cortisol serum levels were lower than normal ranges in $18 \%$ and $25 \%$ MS patients respectively. The intervention resulted in significant reductions in both ACTH and cortisol $(\mathrm{p}<0.001)$, with a more marked ACTH reduction in males compared to females $(p<0.001)$. Post-TVAM BP increased in patients who presented with baseline BP within lower limits of normal ranges, but decreased in patients with baseline BP above the normal ranges. In a univariate analysis, the changes $(\Delta)$ in ACTH serum levels correlated weakly, although significantly, with $\Delta$ in diastolic BP $(r=-0.265, \mathrm{p}=0.03)$, and $\Delta$ in cortisol serum levels correlated weakly, but significantly, with $\Delta$ in systolic BP $(r=-0.283$, $\mathrm{p}=0.01$ ). The observed ACTH and cortisol reductions are counter to the stress-mediated increases in serum levels of these hormones, which are expected following an invasive procedure. The clinical implications of this unexpected response warrant further investigations.

obstructing lesions of the extra-cranial veins, particularly, the internal jugular veins (IJVs) and azygos vein $[1,2]$. Although, subsequent studies have shown that CCSVI is not specific to MS [3,4], endovascular repair, primarily balloon angioplasty (BA) of the venous lesions, has been studied as a potential MS therapeutic modality, with a documented safety profile [5-7].

Venous dilation has been shown to beneficially influence the course of MS, by reducing the rate of clinical relapse, reducing $\mathrm{T} 2$ lesions numbers on the MRI scan, reducing the rate of disease progression, and improving physical and cognitive function [8-10], therefore downregulating inflammatory and neurodegenerative processes. It has also been suggested that the beneficial effects of BA in MS patients is related to BA 
potential for increasing the CSF flow due to improvement in venous drainage [11]. Furthermore, venous BA increases both the arterial and venous blood flow [12], correcting the hypoperfusion, which is the result of venous outflow obstructions [13]. Our recent study shows that BA has also the potential of correcting BP deviation in patients presenting with CCSVI [14]. The effect of BA on BP seems to be through the resetting of high pressure baroreceptors by sensing the degree of changes in central venous pressure; the latter is mediated via changes in volume [15]. However, venous distention could also activate the sympathetic ANS function, independent of changes in volume [16]. These results suggest that BA has the potential for improving ANS dysfunction, often observed in MS patients $[17,18]$.

In our clinical practice, $91 \%$ patients who seek corrective BA present with a combination of internal jugular venous (IJVs) flow obstruction ( $\geq 50 \%$ unilateral or bilateral IJV closure) and clinical symptoms such as cognitive impairment, fatigue, sleeping disorders, headache upon waking up, and thermal intolerance [14]. Cardiovascular ANS dysfunction is known to contribute to these clinical symptoms [19-23], suggesting a relationship between CCSVI and ANS dysfunction.

Marchione et al. [24] have recently reported postural-dependent impairment in cerebral blood flow and cerebral venous flow in MS patients. The authors concluded that these hemodynamic impairments may stem from ANS dysfunction. ANS is known to also regulate the cerebral autoregulation and cerebrovascular tone [25]. MS patients who have ANS dysfunction [17,18] present with impairment of cerebral autoregulation [26]. The ANS vascular deregulation might in turn contribute to venous remodeling [27-30].

Based on the assumption that BA clinical benefits may stem in part from the improvement in cardiovascular ANS function due to venous dilation-induced sympathetic activation, we adopted a modified BA technique with the objective of further enhancing ANS functional activities. This modified BA technique, which we termed Transvascular Autonomic Modulation (TVAM), involves dilation of multiple vascular beds, including IJVs, azygos and renal veins, and application of manual compression. This approach assumed to result in a greater sympathetic ANS stimulation as compared to the traditional BA. Patients who underwent TVAM were selected based on the presence of ANS dysfunction rather than vascular lesions [31].

ANS activation is known to also regulate the elevation in HR and BP during physical and mental stress, via sympathetic-adrenalmedullary axis activation and catecholamine secretion [32]. Accumulated data from in vitro and in vivo studies demonstrate that catecholaminergic input through an adrenergic receptordependent mechanism activates the hypothalamic-pituitaryadrenal (HPA) axis, increasing the expression of the corticotropin releasing hormone $(\mathrm{CRH})[33,34]$. $\mathrm{CRH}$ produced in the paraventricular nucleus of the hypothalamus, in turn stimulates the secretion of the adrenocorticotropic hormone (ACTH) from the anterior lobe of the pituitary gland, which acts on the adrenal cortex to release the stress hormone, cortisol.

In addition to ANS dysfunction, MS patients show alterations in the activity of the HPA axis. Both HPA axis hyperactivity [35-37] and hypoactivity [38-40] have been reported in MS patients. The hyperactivity correlates with the progression of the disease, neurological disability, and cognitive impairment [35-37]. Other studies show a negative correlation between HPA axis hypoactivity and gadolinium enhancing lesions and positive correlation with ventricular volume, and progressive disease course $[38,39]$.
These studies collectively suggest that HPA axis dysregulation, regardless of the direction, may play a role in the pathology of MS. This study determined TVAM effect on HPA axis activity, measuring the changes in ACTH and cortisol serum levels. We also correlated between TVAM-induced changes in serum levels of the 2 hormones and changes in ANS function, measuring changes in BP and HRV parameters.

\section{Material and Methods}

$\nabla$

\section{Population}

The study involved MS patients who visited the Endovascular Clinic (Synergy Health concepts, Newport Beach, CA, USA). A total of 72 (28 males) MS patients, average age $49.6 \pm 11$ years (22-72 years) and disease duration of $12.8 \pm 7.7$ years (1-39 years) with clinical symptoms of cognitive impairment, fatigue, sleeping disorders, headache upon waking up, and thermal intolerance. Among patients, 61 were relapsing remitting (RR), and 11 were chronic progressive (CP) (5 secondary progressive $(\mathrm{SP})$, and 6 were primary progressive (PP). Patients with hypercoaguable state and pregnant patients were excluded from the study.

TVAM deviated from traditional BA in that all of the target vessels, bilateral internal jugular, azygos and left renal vein, were treated regardless of the presence or absence of an abnormality. In this technique, vessels were treated sequentially, starting with the left jugular followed by the right jugular, azygos and finally the left renal vein. Jugular vein dilation was carried out at the level of the valve. Compression was applied during the initial 30 s of jugular balloon inflation by fluoroscopically localizing the inflated balloon in the supraclavicular fossa. Valvular localization was confirmed by IVUS. Balloon sizing was determined by vessel luminal area as calculated by IVUS. Balloon size was such that the vessel would be over-dilated $10-25 \%$ of measured area depicted by IVUS. Kevlar balloons (Bard Peripheral Vascular, Inc, 1625 West $3^{\text {rd }}$ Street, Tempe, AZ 85281, USA) were utilized to deliver maximum pressure with an inflation time of $3 \mathrm{~min}$, the time which was similar to that in the traditional BA procedure.

\section{Assessment of HPA axis and ANS function}

TVAM effects on HPA axis was assessed by measuring ACTH and cortisol serum levels. TVAM effects on cardiovascular ANS function was assessed by measuring BP (indicator of sympathetic activity) and R-R interval (indicator of parasympathetic activity). All measurements were performed before and $24 \mathrm{~h}$ postTVAM intervention. The measurements were performed at the same time \pm 2 h during the day, in a room in which the temperature was tightly regulated at $70^{\circ} \mathrm{C}$, due to thermal sensitivities of the patient population.

ACTH and cortisol serum levels were measured by electrochemiluminescence Immunoassay (ECLIA) methodology by an outside lab facility. A single measurement of systolic and diastolic $\mathrm{BP}$ was performed manually, by a sphygmomanometer, in sitting position. R-R interval was measured by determining the expiration/inspiration (E/I) ratio, the Valsalva ratio, and the $30: 15$ postural ratio. Deep breathing, Valsalva maneuver, and standing from a supine position were respectively used as appropriate stimuli for these tests. HRV was analyzed using the ANS 2000 (D.E. Hokanson, Inc. 12840 NE 21 ${ }^{\text {st }}$ Place, Bellevue, WA 98005, USA). Methods for HRV measurements have been previously described [41]. 
The clinical assessment of fatigue (both physical and mental fatigue) was done by the Modified Fatigue Impact Scale; cognitive impairment was defined as the loss of intellectual functions and trouble with verbal recall, basic arithmetic; concentration was measured by Perceived Deficits Questionnaire; thermal dysregulation sleeping disorder, headache upon awakening, were assessed with customized questions using a 1-5 scale for consistency.

\section{Follow-up}

Post-procedure recovery consisted of direct $2 \mathrm{~h}$ observation, during which time, oral administration of anticoagulation with Rivaroxaban was initiated. Rivaroxaban $15 \mathrm{mg} /$ day was continued for 90 days. Jugular duplex Doppler was performed at $24 \mathrm{~h}$ postprocedure and at 3 months following cessation of Rivaroxaban.

\section{Statistical analysis}

All statistical analyses were performed using SPSS 14.0 for Windows (SPSS Institute, Chicago, Illinois, USA). Repeated ANOVA was used to examine the differences in $\mathrm{ACTH} /$ cortisol serum levels, in systolic/diastolic BP readings, and R-R intervals before and after TVAM. ANOVA also measured the differences in the measured variables between males and females, and between RRMS/ CPMS patients. Multiple regressions determined the association between ACTH/cortisol and ANS function tests.

A consent form was signed by each subject before the TVAM intervention. IRB permission was obtained to allow the extraction of clinical data from patients' chart.

\section{Results}

\section{Post-intervention adverse events}

No intra-procedural adverse events occurred, specifically, no evidence of vascular injury was identified. Mild headache, mild body aches, and mild dizziness were noted in the treated group. All side effects resolved within $72 \mathrm{~h}$.

\section{ACTH and cortisol responses to TVAM}

- Fig. 1 shows (mean \pm SEM) ACTH ( $\bullet$ Fig. 1a) and cortisol ( $\odot$ Fig. 1b) serum levels, stratified by gender, before and after the TVAM procedure.

ACTH serum levels were reduced by $34.8 \%$ post-TVAM intervention relative to baseline $(13.8 \pm 1.0 \mathrm{pg} / \mathrm{ml}$ vs. $8.0 \pm 1.3 \mathrm{pg} / \mathrm{ml}$, $\mathrm{p}<0.001)$. These reductions were significant for both males $(18.0 \pm 2.0 \mathrm{pg} / \mathrm{ml}$ vs. $6.6 \pm 1.1 \mathrm{pg} / \mathrm{ml}, \mathrm{p}<0.001)$ and females $(11.0 \pm 0.9 \mathrm{pg} / \mathrm{ml}$ vs. $9.0 \pm 2.0 \mathrm{pg} / \mathrm{ml}, \mathrm{p}<0.001)$. Baseline ACTH serum levels $(18.0 \pm 2.0 \mathrm{pg} / \mathrm{ml}$ vs. $11.0 \pm 1.0 \mathrm{pg} / \mathrm{ml}, \mathrm{p}<0.001)$, and the post-TVAM changes $(\Delta)$ in ACTH serum levels $(11.2 \pm 2.3 \mathrm{pg} /$ $\mathrm{ml}$, vs. $2.2 \pm 2.0 \mathrm{pg} / \mathrm{ml}, \mathrm{p}<0.001$ ) were higher in males compared to females.

Among patients, $18.5 \%$ (18.5\% below the normal range, $0 \%$ above the normal range) had baseline ACTH serum levels outside the normal ranges $(7.2-63.3 \mathrm{pg} / \mathrm{ml})$. These percentages were increased to $78.2 \%$ ( $75.3 \%$ below the normal range and 3\% above the normal range) post-TVAM procedure.

TVAM intervention led to a $31 \%$ reduction in cortisol serum levels relative to baseline $(10.7 \pm 0.6 \mathrm{pg} / \mathrm{ml}$ vs. $7.4 \pm 0.8 \mathrm{pg} / \mathrm{ml}$, $\mathrm{p}<0.001)$. Gender stratification showed significant reduction in cortisol serum levels post-TVAM procedure for both males $(12.2 \pm 1.0 \mathrm{pg} / \mathrm{ml}$ vs. $8.1 \pm 1.6 \mathrm{pg} / \mathrm{ml}, \mathrm{p}=0.001)$ and females $(9.8 \pm 0.7 \mathrm{pg} / \mathrm{ml}$ vs. $6.9 \pm 0.9 \mathrm{pg} / \mathrm{ml}, \mathrm{p}<0.001)$. Baseline cortisol

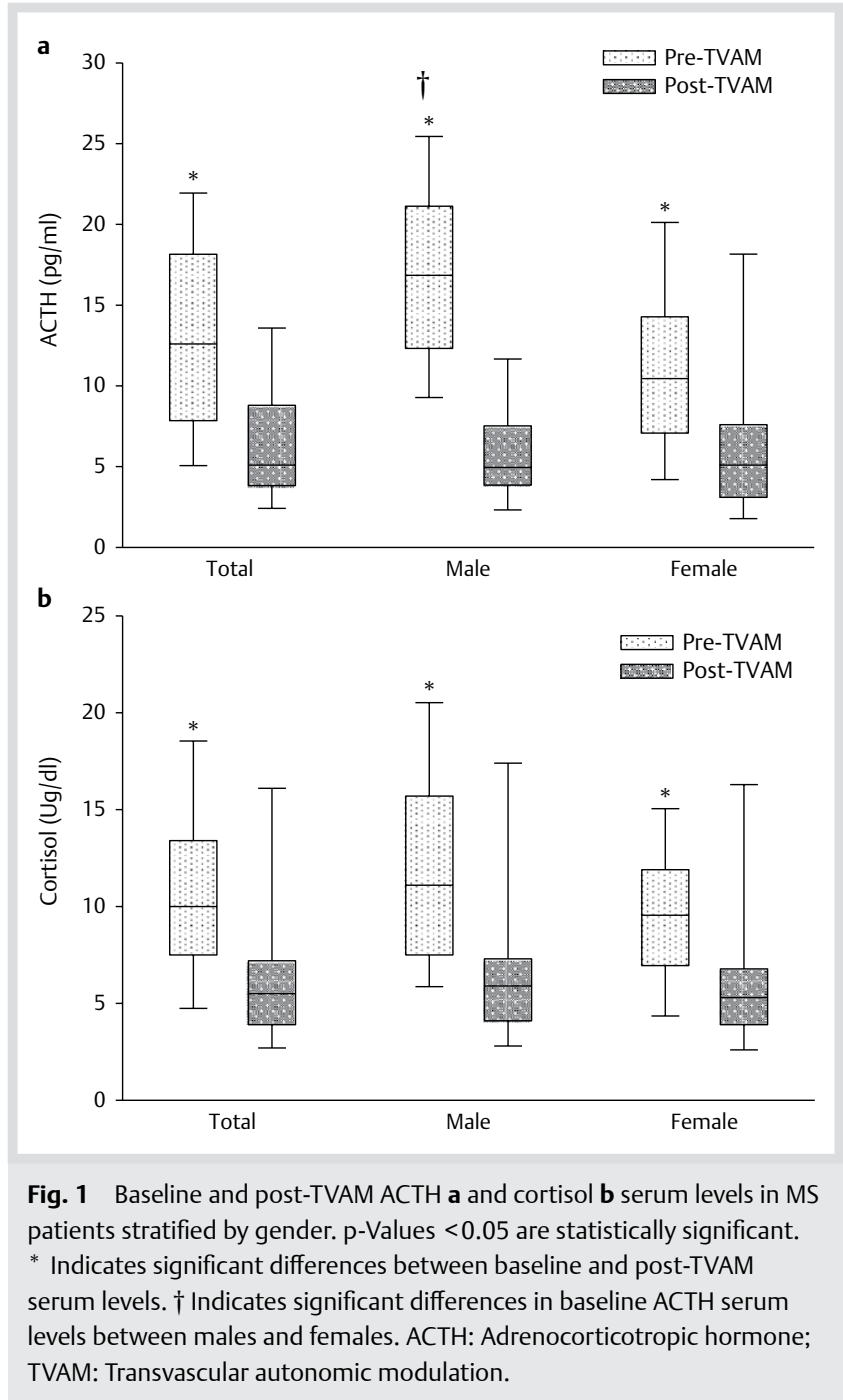

serum levels $(12.2 \pm 1.0 \mathrm{pg} / \mathrm{ml}$ vs. $9.8 \pm 0.7 \mathrm{pg} / \mathrm{ml})$, and post-TVAM cortisol serum levels $(8.1 \pm 1.6 \mathrm{pg} / \mathrm{ml}$ vs. $6.9 \pm 0.9 \mathrm{pg} / \mathrm{ml})$ tended to be higher in males compared to females, but these differences did not reach statistical significance (all p-values $>0.05$ ) ( $\odot$ Fig. 1b). At baseline, $25.3 \%$ (18.3\% below the normal ranges, and $7.0 \%$ above the normal ranges) had cortisol serum levels outside the normal ranges $(6.2-19.4 \mathrm{pg} / \mathrm{ml})$. These percentages were increased to $75.3 \%$ (68.2\% below the normal ranges, and $7.2 \%$ above the normal ranges) post-TVAM procedure.

\section{ACTH and cortisol response subcategories}

$\odot$ Fig. 2 presents the percent reductions in ACTH ( $\odot$ Fig. $\mathbf{2 a}$ ) and cortisol ( $\Theta$ Fig. 2b) serum levels, post-TVAM procedure, relative to baseline levels. These percentages are subcategorized to lower than normal range, (ACTH: $<7.2 \mathrm{pg} / \mathrm{ml}$, cortisol: $<6.2 \mathrm{pg} / \mathrm{ml}$ ), gradually doubling it at each subsequent level.

The reduction in ACTH and cortisol serum levels depended on the baseline levels of the 2 hormones. ACTH serum levels were reduced by $52.4 \%, 46.4 \%$, and $77.6 \%$ in patients with baseline ACTH serum levels $\geq 7.2-14.4 \mathrm{pg} / \mathrm{ml}, 14.5-21.6 \mathrm{pg} / \mathrm{ml}$, and $\geq 21.6 \mathrm{pg} /$ $\mathrm{ml}$, respectively ( $\mathrm{p}$-values between $<0.001-0.03$ ). However, post-TVAM reductions in ACTH serum levels were not significant in patients who had baseline ACTH serum levels below $7.2 \mathrm{pg} / \mathrm{ml}$ ( $16.3 \%$ reduction, $p=0.30$ ) ( $\odot$ Fig. $2 a$ ). 


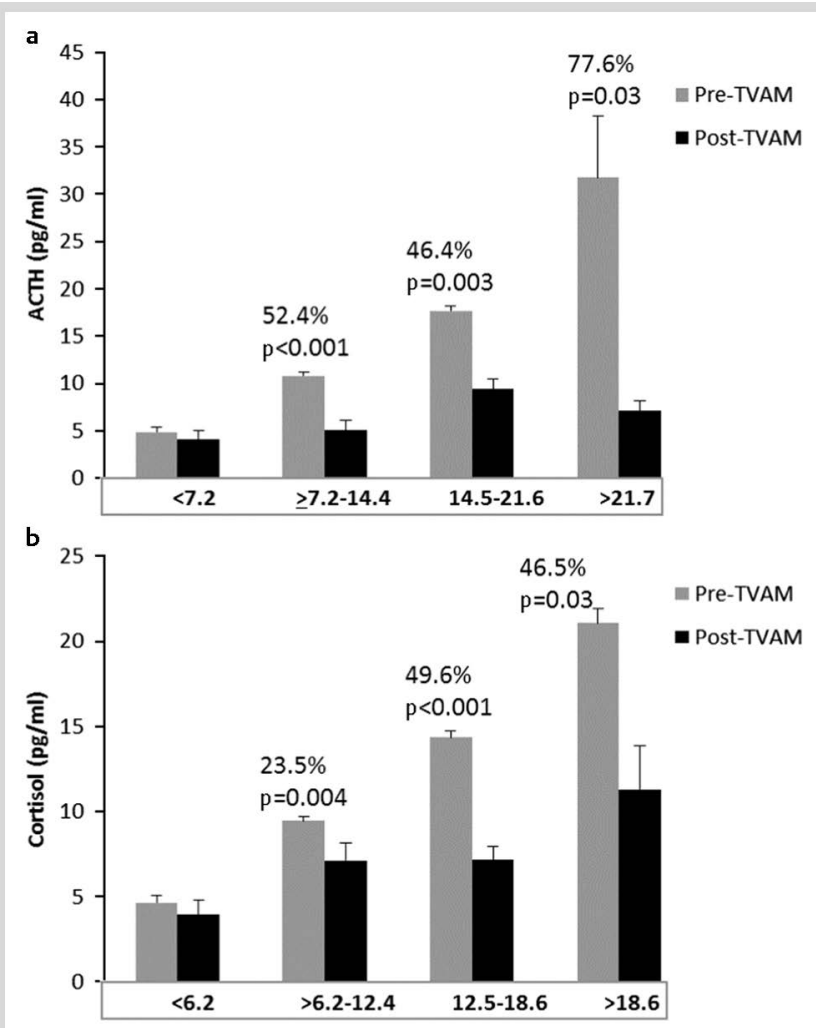

Fig. 2 Reduction in ACTH a and cortisol $\mathbf{b}$ serum levels post-TVAM procedure as functions of baseline ACTH serum levels ranging from $<7.2$ to $>21.7 \mathrm{pg} / \mathrm{ml}$, and baseline cortisol levels ranging from $<6.2$ to $18.6 \mathrm{pg} /$ $\mathrm{ml}$. The percent reduction in ACTH/cortisol serum levels and the associated p-values are calculated and depicted for each baseline ACTH and cortisol interval. Abbreviations as in $\bullet$ Fig. 1.

Cortisol serum levels were reduced by $23.5 \%, 49.6 \%$, and $46.5 \%$ in patients with baseline cortisol levels $>6.2-12.4 \mathrm{pg} / \mathrm{ml}, 12.5-$ $18.6 \mathrm{pg} / \mathrm{ml}$, and $>18.6 \mathrm{pg} / \mathrm{ml}$ respectively ( $\mathrm{p}$-values between $<0.001-$ 0.03 ), but post-TVAM reductions in cortisol serum levels were not significant in patients who had baseline cortisol serum levels below $6.2 \mathrm{mg} / \mathrm{ml}$ (14.6\% reduction, $\mathrm{p}=0.12$ ) ( $\odot$ Fig. $\mathbf{2 b}$ ).

Comparison of the cortisol/ACTH ratio pre-TVAM relative to post-TVAM demonstrated a significantly lower cortisol/ACTH ratio, pre-TVAM procedure compared to the same ratio postTVAM procedure ( 0.96 vs. $1.35, \mathrm{p}<0.002)$, suggesting a larger ACTH than cortisol reduction post-TVAM procedure. The differences in pre- to post-cortisol/ACTH ratio was significant in males (0.81 vs. $1.55, \mathrm{p}<0.003)$, but not in females (1.05 vs. 1.22, $\mathrm{p}=0.20)$.

- Fig. 3 shows the mean \pm SEM of ACTH ( $\odot$ Fig. $3 a$ ) and cortisol ( $\odot$ Fig. 3b) serum levels, stratified by disease stage, before and after TVAM procedure. The CPMS group is comprised of SPMS and PPMS patients $(n=11)$. The results are corrected for group differences in age, gender and disease duration.

Both RRMS $(14.0 \pm 1.1 \mathrm{pg} / \mathrm{ml}$ vs. $8.6 \pm 1.5 \mathrm{pg} / \mathrm{ml}, \mathrm{p}<0.001)$ and CPMS $(12.8 \pm 2.1 \mathrm{pg} / \mathrm{ml}$ vs. $4.8 \pm 0.5 \mathrm{pg} / \mathrm{ml}, \mathrm{p}=0.005)$ patients showed significant reductions in ACTH serum levels post-TVAM procedure relative to baseline ( $\bullet$ Fig. 3a). In addition, both RRMS $(10.8 \pm 0.6 \mathrm{pg} / \mathrm{ml}$ vs. $7.8 \pm 0.9 \mathrm{pg} / \mathrm{ml}, \quad \mathrm{p}<0.001)$ and CPMS $(10.4 \pm 2.0 \mathrm{pg} / \mathrm{ml}$ vs. $4.9 \pm 1.0 \mathrm{pg} / \mathrm{ml}, \mathrm{p}=0.002)$ patients showed significant reductions in cortisol serum levels post-TVAM procedure ( $\odot$ Fig. 3b). Baseline and post-TVAM ACTH and cortisol serum levels tended to be lower in CPMS compared to RRMS

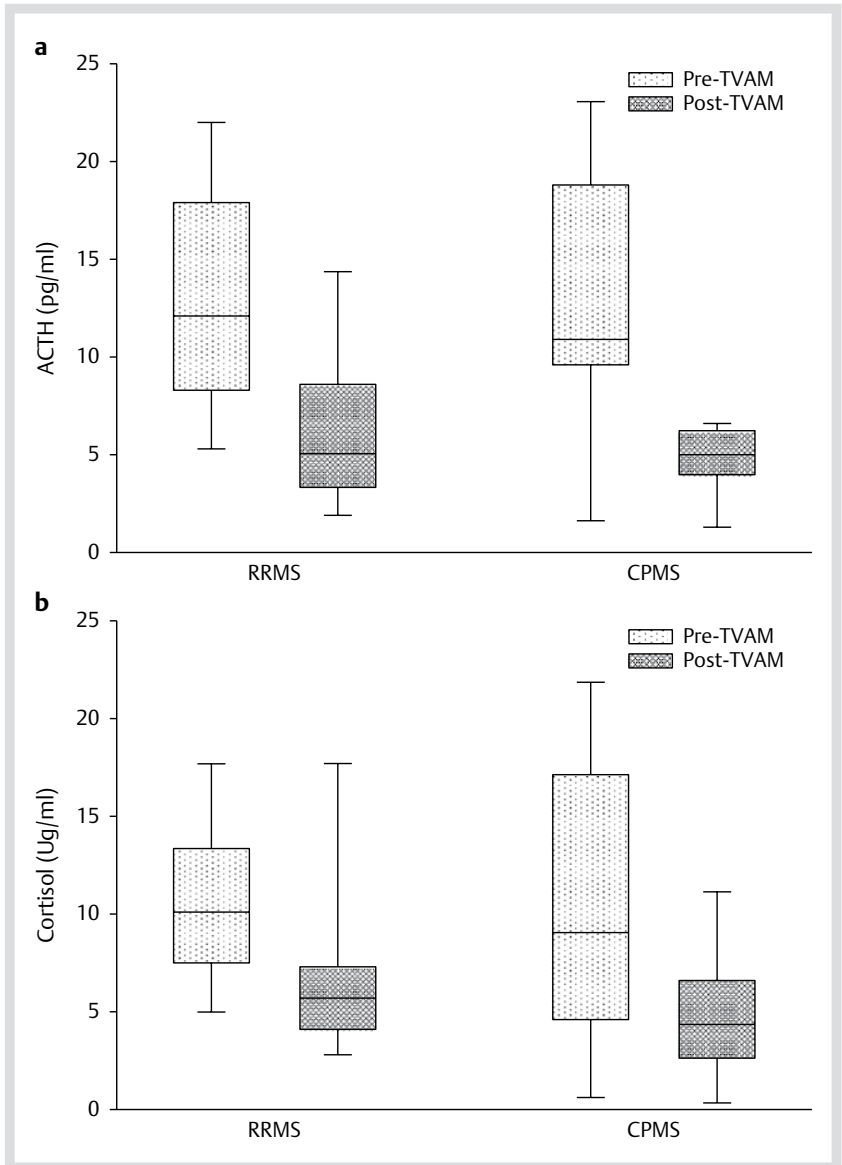

Fig. 3 Baseline and post-TVAM ACTH $\mathbf{a}$ and cortisol $\mathbf{b}$ serum levels in MS patients stratified by disease stage. $p$-Values $<0.05$ are statistically significant. ${ }^{*}$ Indicates significant differences between baseline and post-BA serum levels. Abbreviations as in $\odot$ Fig. 1 and CPMS: Chronic progressive multiple sclerosis; RRMS: Relapsing-remitting multiple sclerosis.

patients, but these differences were not statistically significant (all p-values $>0.05$ ).

\section{Cardiovascular Autonomic Response to TVAM $\nabla$}

\section{BP response to TVAM}

- Table 1-A shows the effect of TVAM on systolic and diastolic BP. Among MS patients, the baseline systolic and diastolic BP ranged between 88 to $172 \mathrm{~mm} \mathrm{Hg}$ and from 48 to $99 \mathrm{~mm} \mathrm{Hg}$ respectively. TVAM reduced the total systolic BP (from $117.5 \pm 2.1 \mathrm{~mm}$ $\mathrm{Hg}$ to $113.5 \pm 2.1 \mathrm{~mm} \mathrm{Hg}, \mathrm{p}=0.04$ ) but not diastolic BP (from $72.2 \pm 1.2 \mathrm{~mm} \mathrm{Hg}$ to $72.3 \pm 1.2 \mathrm{~mm} \mathrm{Hg}, \mathrm{p}>0.05$ ).

Subsequently, we categorized systolic and diastolic BP from lower than normal ranges (systolic BP: $88-105 \mathrm{~mm} \mathrm{Hg}$, diastolic BP: 48-65 mm Hg), above normal ranges (systolic BP: 116$172 \mathrm{~mm} \mathrm{Hg}$, diastolic BP: 76-99 mm Hg), and within normal ranges (systolic BP: $106-115 \mathrm{~mm} \mathrm{Hg}$, diastolic BP: $66-75 \mathrm{~mm}$ $\mathrm{Hg}$ ), allowing adequate number of patients in each subcategory for optimal power analysis.

This subcategorization showed multiphasic effect of TVAM on BP. At lower than normal ranges, TVAM increased both systolic $(98.1 \pm 1.2 \mathrm{~mm} \mathrm{Hg}$ vs. $105.6 \pm 2.4 \mathrm{~mm} \mathrm{Hg}, \mathrm{p}=0.01)$ and diastolic (58.1 $\pm 1.3 \mathrm{~mm} \mathrm{Hg}$ vs. $63.5 \pm 2.3 \mathrm{~mm} \mathrm{Hg}, \mathrm{p}=0.008$ ) BP, with a more marked effect on diastolic BP. However, at above normal ranges of BP, TVAM significantly reduced the systolic $(133.4 \pm 2.5 \mathrm{~mm} \mathrm{Hg}$ 
Table 1 Sympathetic (BP) and parasympathetic ( $R$-R interval) function tests.

\begin{tabular}{|c|c|c|c|}
\hline & Pre-TVAM & Post -TVAM & p-Value \\
\hline \multicolumn{4}{|c|}{ A. Sympathetic function } \\
\hline \multicolumn{4}{|l|}{ Systolic BP (mm Hg) } \\
\hline Total (88-172) & $117.5 \pm 2.1$ & $113.5 \pm 2.1$ & 0.04 \\
\hline $88-105$ & $98.1 \pm 1.2$ & $105.6 \pm 2.4$ & 0.01 \\
\hline $106-115$ & $110.0 \pm 0.7$ & $106.0 \pm 2.4$ & 0.15 \\
\hline $116-172$ & $133.4 \pm 2.5$ & $123.0 \pm 3.5$ & 0.001 \\
\hline \multicolumn{4}{|l|}{ Diastolic BP (mm Hg) } \\
\hline Total (48-99) & $72.2 \pm 1.2$ & $72.3 \pm 1.2$ & 0.96 \\
\hline $48-65$ & $58.1 \pm 1.3$ & $63.5 \pm 2.3$ & 0.008 \\
\hline $66-75$ & $70.4 \pm 0.5$ & $69.7 \pm 1.0$ & 0.43 \\
\hline $76-99$ & $84.0 \pm 1.4$ & $81.6 \pm 1.7$ & 0.11 \\
\hline \multicolumn{4}{|c|}{ B. Parasympathetic function } \\
\hline E/I ratio & $1.094 \pm 0.0$ & $1.10 \pm 0.0$ & 0.75 \\
\hline Valsalva ratio & $1.83 \pm 0.06$ & $1.76 \pm 0.05$ & 0.21 \\
\hline 30:15 Postural ratio & $1.21 \pm 0.05$ & $1.71 \pm 0.30$ & 0.21 \\
\hline
\end{tabular}

Abbreviations as in Fig. 1-3. E/l: Expiration/inspiration ratio p-Values $<0.05$ are significant

vs. $123.0 \pm 3.5 \mathrm{~mm} \mathrm{Hg}, \mathrm{p}=0.001)$ but not the diastolic $(84.0 \pm 1.4 \mathrm{~mm}$ $\mathrm{Hg}$ vs. $81.6 \pm 1.7 \mathrm{mmHg}, \mathrm{p}=0.10)$ BP. TVAM had no significant effect on systolic $(110.0 \pm 0.7 \mathrm{mmHg}$ vs. $106.0 \pm 2.4 \mathrm{~mm} \mathrm{Hg})$ and diastolic (70.4 $\pm 0.5 \mathrm{~mm} \mathrm{Hg}$ vs. $69.7 \pm 1.0 \mathrm{~mm} \mathrm{Hg}$ ) BP within the normal ranges (all p-values $>0.05$ ).

\section{R-R interval response to TVAM}

- Table 1-B shows the effect of TVAM on R-R interval. TVAM increased $\mathrm{E} / \mathrm{I}$ ratio ( $1.094 \pm 0.0$ vs. $1.10 \pm 0.0$ ), and $30: 15$ postural ratio $(1.21 \pm 0.05$ vs. $1.71 \pm 0.30)$, but reduced Valsalva ratio $(1.83 \pm 0.06$ vs. $1.76 \pm 0.05)$, however, none of these changes were statistically significant ( $\mathrm{p}$-values $>0.05$ ). Among patients, $85.7 \%$, $29.2 \%, 11.5 \%$ had E/I ratio, 30:15 postural ratio and Valsalva ratio below the normal ranges respectively. These percentages stood at $76.2 \%, 20.8 \%$, and $14.7 \%$ Post-TVAM procedure.

\section{Correlation between ACTH-cortisol and BP-HRV Parameters \\ $\nabla$}

Subsequently, we correlated ACTH and cortisol serum levels with BP and HRV parameters. Overall, the association between ACTH and cortisol and BP was negative. These associations reached statistical significance for post-TVAM changes $(\Delta)$ in ACTH serum levels and post-TVAM changes in diastolic BP $(r=-0.265, \mathrm{p}=0.03)$, and between post-TVAM changes in cortisol serum levels and post-TVAM changes in systolic BP $(r=-0.283, \mathrm{p}=0.01)$. We did not observe a significant relationship between ACTH or cortisol serum levels and HRV parameters, nor between ACTH or cortisol serum levels and age or disease duration.

\section{Discussion}

$\nabla$

We measured the activity of 2 major stress response systems, the HPA axis and the ANS, before and $24 \mathrm{~h}$ after TVAM intervention in MS patients. This is the first study measuring endocrine responses to venous dilation in MS patients, presenting with clinical symptoms of cognitive impairment, fatigue, sleeping disorder, headache upon awakening, and thermal dysregulation, clinical symptoms which are known to involve ANS dysfunction as part of the clinical picture [19-23].

Consistent with earlier studies [38-40], we observed lower than normal baseline ACTH and cortisol serum levels in 18\% and 25\% of patients respectively. This hypoactivity was more pronounced during dynamic HPA responses to TVAM. In addition, the degree of post-TVAM reduction in the 2 hormones was positively associated with baseline levels of the 2 hormones.

These post-TVAM reductions are counter to the stress-mediated increases in ACTH and cortisol serum levels expected following an invasive procedure [42], although the directionality of the HPA axis response (hyper-reactive or hypo-reactive) to a stressor has been shown to depend on the type (physical, psychological, pharmacological) and duration (acute vs. chronic) of the applied stressor [43].

A number of factors could lead to TVAM-induced HPA axis hypoactivity in MS patients. For example, the suppression of $\mathrm{CRH}$ neurons by active MS lesions, the majority of which are located in the hypothalamus, has been thought to contribute to HPA hypoactivity [38]. In addition, studies in the chronic relapsing experimental autoimmune encephalomyelitis (EAE) model show that disease progression reduces $\mathrm{CRH}$ responses to stimuli, leading to HPA axis desensitization [44]. This line of thought is consistent with our observation of a trend toward more steeper post-TVAM reductions in ACTH and cortisol serum levels in CPMS as compared to RRMS patients. Nevertheless, one could argue that anticholinergic effects of Rivaroxaban administration can lead to ANS dysfunction and HPA axis hypoactivity. We argue that the HPA axis hypoactivity is present also at baseline before TVAM procedure and Rivaroxaban administration.

Both physiological [45] and psychological [46] stress are known to increase cerebral blood flow, although this increase regional, involving redistribution of blood flow, following Monro-Kelly law. Nevertheless, a rise in plasma levels of stress hormones [45] and $\beta$-adrenergic receptors' activation [47] are prerequisite for the observed changes in cerebral blood flow. Whether MS cerebral $\beta$-adrenergic dysfunction [48] plays a role in HPA axis hypoactivity [38-40] and reduced MS cerebral blood flow [13] warrants further investigations.

HPA axis response to TVAM was gender dependent, with significant differences in cortisol/ACTH ratio pre-TVAM procedure relative to post-TVAM procedure in males, as compared to females. Gender differences in HPA axis in MS patients have not been studied, but have been shown to depend on the type of the stimulus, with males showing higher ACTH and cortisol responses to psychological [49] and physical [50] stimuli, whereas female show higher reactivity to pharmacological stimuli [49]. The lesser reduction in ACTH serum levels post-TVAM in females may be associated with the ability of estradiol to modulate glucocorticoid (-) feedback within the hypothalamus [51], although some of these differences exist even in the absence of characteristic differences in reproductive steroids [50].

\section{Study limitations}

We have shown, for the first time, TVAM-induced endocrine changes in MS patients, and confirmed our earlier results on TVAM-induced changes in ANS function. However, our data is limited to one measurement before and one measurement postTVAM intervention. We do not have long term data on these patients, and therefore one cannot determine whether changes in stress hormones are long lasting, and or influencing and 
course of the disease. In addition, our study does not include a control group, and therefore, we do not know whether the postTVAM and post-BA alterations in endocrine hormones follow similar pattern in patient with and without vascular lesions.

\section{Conflict of Interest}

$\nabla$

The authors declare no conflict of interest.

\section{References}

1 Zamboni P, Galeotti R, Menegatti E, Malagoni AM, Tacconi G, Dall'Ara $S$, Bartolomei I, Salvi F. Chronic cerebrospinal venous insufficiency in patients with multiple sclerosis. J Neurol Neurosurg Psychiatr 2009; 80: 392-399

2 Bartolomei I, Salvi F, Galeotti R, Salviato E, Alcanterini M, Menegatti $E$, Mascalchi M, Zamboni P. Hemodynamic patterns of chronic cerebrospinal venous insufficiency in multiple sclerosis. Correlation with symptoms at onset and clinical course. Int Angiol 2010; 29: 183-188

3 Traboulsee AL, Knox KB, Machan L, Zhao Y, Yee I, Rauscher A, Klass D, Szkup P, Otani R, Kopriva D, Lala S, Li DK, Sadovnick D. Prevalence of extracranial venous narrowing on catheter venography in people with multiple sclerosis, their siblings, and unrelated healthy controls: a blinded, case-control study. Lancet 2014; 383: 138-145

4 Comi G, Battaglia MA, Bertolotto A, Del Sette M, Ghezzi A, Malferrari G, Salvetti M, Sormani MP, Tesio L, Stolz E, Zaratin P, Mancardi G. Observational case-control study of the prevalence of chronic cerebrospinal venous insufficiency in multiple sclerosis: results from the CoSMo study. Mult Scler 2013; 19: 1508-1517

5 Ludyga T, Kazibudzki M, Simka M, Hartel M, Swierad M, Piegza J, Latacz $P$, Sedlak L, Tochowicz M. Endovascular treatment for chronic cerebrospinal venous insufficiency: is the procedure safe? Phlebology 2010; 25: 286-295

6 Mandato KD, Hegener PF, Siskin GP, Haskal ZJ, Englander MJ, Garla $S$, Mitchell N, Reutzel L, Doti C. Safety of endovascular treatment of chronic cerebrospinal venous insufficiency: a report of 240 patients with multiple sclerosis. J Vasc Interv Radiol 2012; 23: 55-59

7 Petrov I, Grozdinski L, Kaninski G, Iliev N, Iloska M, Radev A. Safety profile of endovascular treatment for chronic cerebrospinal venous insufficiency in patients with multiple sclerosis. J Endovasc Therap 2011; 18: 314-323

8 Zamboni P, Galeotti R, Weinstock-Guttman B, Kennedy C, Salvi F, Zivadinov $R$. Venous angioplasty in patients with multiple sclerosis: results of a pilot study. Eur J Vasc Endovasc Surg 2012; 43: 116-122

9 Salvi F, Bartolomei I, Buccellato E, Galeotti R, Zamboni P. Venous angioplasty in multiple sclerosis: neurological outcome at two years in a cohort of relapsing-remitting patients. Funct Neurol 2012; 27: 55-59

10 Hubbard D, Ponec D, Gooding J, Saxon R, Sauder H, Haacke M. Clinical improvement after extracranial venoplasty in multiple sclerosis. J Vasc Interv Radiol 2012; 23: 1302-1308

11 Zivadinov R, Magnano C, Galeotti R, Schirda C, Menegatti E, WeinstockGuttman B, Marr K, Bartolomei I, Hagemeier J, Malagoni AM, Hojnacki $D$, Kennedy C, Carl E, Beggs C, Salvi F, Zamboni P. Changes of cine cerebrospinal fluid dynamics in patients with multiple sclerosis treated with percutaneous transluminal angioplasty: a case-control study. J Vasc Interv Radiol 2013; 24: 829-838

12 Thibault $P$, Lewis $W$, Niblett $S$. Objective duplex ultrasound evaluation of the extracranial circulation in multiple sclerosis patients undergoing venoplasty of internal jugular vein stenoses: A pilot study. Phlebology 2013; doi:10.1177/0268355513515473

13 Zamboni P, Menegatti E, Weinstock-Guttman B, Dwyer MG, Schirda CV, Malagoni AM, Hojnacki D, Kennedy C, Carl E, Bergsland N, Magnano C, Bartolomei I, Salvi F, Zivadinov R. Hypoperfusion of brain parenchyma is associated with the severity of chronic cerebrospinal venous insufficiency in patients with multiple sclerosis: a cross-sectional preliminary report. BMC Med 2011; 9: 22

14 Sternberg Z, Grewal P, Cen S, Debarge-Igoe F, Yu J, Arata M. Blood pressure normalization post-jugular venous balloon angioplasty. Phlebology 2013; doi:10.1177/0268355513512824

15 Zoller RP, Mark AL, Abboud FM, Schmid PG, Heistad DD. The role of low pressure baroreceptors in reflex vasoconstrictor responses in man. J Clin Invest 1972; 51: 2967-2972
16 Cui J, McQuillan PM, Blaha C, Kunselman AR, Sinoway LI. Limb venous distension evokes sympathetic activation via stimulation of the limb afferents in humans. Am J Physiol Heart Circulat Physiol 2012; 303: $\mathrm{H} 457-\mathrm{H} 463$

17 Sanya EO, Tutaj M, Brown CM, Goel N, Neundorfer B, Hilz MJ. Abnormal heart rate and blood pressure responses to baroreflex stimulation in multiple sclerosis patients. Clin Autonom Res 2005; 15: 213-218

18 Flachenecker P, Reiners K, Krauser M, Wolf A, Toyka KV. Autonomic dysfunction in multiple sclerosis is related to disease activity and progression of disability. Mult Scler 2001; 7: 327-334

19 Ross AJ, Medow MS, Rowe PC, Stewart JM. What is brain fog? An evaluation of the symptom in postural tachycardia syndrome. Clin Autonom Res 2013; 23: 305-311

20 Martinez-Martinez LA, Mora T, Vargas A, Fuentes-Iniestra M, MartinezLavin $M$. Sympathetic nervous system dysfunction in fibromyalgia, chronic fatigue syndrome, irritable bowel syndrome, and interstitial cystitis: a review of case-control studies. J Clin Rheumatol 2014; 20 : 146-150

21 Mallien J, Isenmann S, Mrazek A, Haensch CA. Sleep disturbances and autonomic dysfunction in patients with postural orthostatic tachycardia syndrome. Front Neurol 2014; 5: 118

22 Peroutka SJ. Migraine: a chronic sympathetic nervous system disorder. Headache 2004; 44: 53-64

23 Hilz MJ, Kolodny EH, Neuner I, Stemper B, Axelrod FB. Highly abnormal thermotests in familial dysautonomia suggest increased cardiac autonomic risk. J Neurol Neurosurg Psychiatr 1998; 65: 338-343

24 Marchione P, Morreale M, Giacomini P, Izzo C, Pontecorvo S, Altieri $M$, Bernardi S, Frontoni M, Francia A. Ultrasonographic evaluation of cerebral arterial and venous haemodynamics in multiple sclerosis: a case-control study. PloS One 2014; 9: e111486

25 Zhang $R$, Zuckerman JH, Iwasaki K, Wilson TE, Crandall CG, Levine $B D$. Autonomic neural control of dynamic cerebral autoregulation in humans. Circulation 2002; 106: 1814-1820

26 Mezei Z, Olah L, Kardos L, Kovacs RK, Csiba L, Csepany T. Cerebrovascular hemodynamic changes in multiple sclerosis patients during headup tilt table test: effect of high-dose intravenous steroid treatment. J Neurol 2013; 260: 2335-2342

27 Lee BB, Baumgartner I, Berlien P, Bianchini G, Burrows P, Gloviczki P, Huang Y, Laredo J, Loose DA, Markovic J, Mattassi R, Parsi K, Rabe E, Rosenblatt $M$, Shortell C, Stillo F, Vaghi M, Villavicencio L, Zamboni P. Diagnosis and Treatment of Venous Malformations Consensus Document of the International Union of Phlebology (IUP): updated 2013. Int Angiol 2014; Feb 25 [Epub ahead of print]

28 Pascolo L, Gianoncelli A, Rizzardi C, Tisato V, Salome M, Calligaro C, Salvi F, Paterson D, Zamboni P. Calcium micro-depositions in jugular truncular venous malformations revealed by Synchrotron-based XRF imaging. Sci Rep 2014; 4: 6540

29 Zamboni P, Tisato V, Menegatti E, Mascoli F, Gianesini S, Salvi F, Secchiero $P$. Ultrastructure of internal jugular vein defective valves. Phlebology 2014; doi:10.1177/0268355514541980

30 Coen M, Menegatti E, Salvi F, Mascoli F, Zamboni P, Gabbiani G, Bochaton-Piallat ML. Altered collagen expression in jugular veins in multiple sclerosis. Cardiovasc Pathol 2013; 22: 33-38

31 Arata M, Sternberg Z. Transvascular Autonomic Modulation: A modified balloon angioplasty technique for the treatment of autonomic dysfunction in multiple sclerosis patients. J Endovasc Therap 2014; 21: 417-428

32 Huang CJ, Webb HE, Zourdos MC, Acevedo EO. Cardiovascular reactivity, stress, and physical activity. Front Physiol 2013; 4: 314

33 Plotsky PM. Facilitation of immunoreactive corticotropin-releasing factor secretion into the hypophysial-portal circulation after activation of catecholaminergic pathways or central norepinephrine injection. Endocrinology 1987; 121: 924-930

34 Plotsky PM, Cunningham ET Jr, Widmaier EP. Catecholaminergic modulation of corticotropin-releasing factor and adrenocorticotropin secretion. Endocr Rev 1989; 10: 437-458

35 Kern S, Krause I, Horntrich A, Thomas K, Aderhold J, Ziemssen T. Cortisol awakening response is linked to disease course and progression in multiple sclerosis. PloS One 2013; 8: e60647

36 Gold SM, Raji A, Huitinga I, Wiedemann K, Schulz KH, Heesen C. Hypothalamo-pituitary-adrenal axis activity predicts disease progression in multiple sclerosis. J Neuroimmunol 2005; 165: 186-191

37 Heesen C, Gold SM, Raji A, Wiedemann K, Schulz KH. Cognitive impairment correlates with hypothalamo-pituitary-adrenal axis dysregulation in multiple sclerosis. Psychoneuroendocrinology 2002; 27: 505-517 
38 Huitinga I, Erkut ZA, van Beurden D, Swaab DF. Impaired hypothalamus-pituitary-adrenal axis activity and more severe multiple sclerosis with hypothalamic lesions. Ann Neurol 2004; 55: 37-45

39 Schumann EM, Kumpfel T, Then Bergh F, Trenkwalder C, Holsboer F, Auer DP. Activity of the hypothalamic-pituitary-adrenal axis in multiple sclerosis: correlations with gadolinium-enhancing lesions and ventricular volume. Ann Neurol 2002; 51: 763-767

40 Melief J, de Wit SJ, van Eden CG, Teunissen C, Hamann J, Uitdehaag BM, Swaab D, Huitinga I. HPA axis activity in multiple sclerosis correlates with disease severity, lesion type and gene expression in normalappearing white matter. Acta Neuropathol 2013; 126: 237-249

41 Maser RE, Lenhard MJ, Rizzo AA, Vasile AA. Continuous positive airway pressure therapy improves cardiovascular autonomic function for persons with sleep-disordered breathing. Chest 2008; 133: 86-91

42 Desborough JP. The stress response to trauma and surgery. Br J Anaesth 2000; 85: 109-117

43 Heesen C, Gold SM, Huitinga I, Reul JM. Stress and hypothalamic-pituitary-adrenal axis function in experimental autoimmune encephalomyelitis and multiple sclerosis - a review. Psychoneuroendocrinology 2007; 32: 604-618

44 Stefferl A, Storch MK, Linington C, Stadelmann C, Lassmann H, Pohl T, Holsboer F, Tilders FJ, Reul JM. Disease progression in chronic relapsing experimental allergic encephalomyelitis is associated with reduced inflammation-driven production of corticosterone. Endocrinology 2001; 142: 3616-3624

45 Page KA, Arora J, Qiu M, Relwani R, Constable RT, Sherwin RS. Small decrements in systemic glucose provoke increases in hypothalamic blood flow prior to the release of counterregulatory hormones. Diabetes 2009; 58: 448-452
46 Wang J, Rao H, Wetmore GS, Furlan PM, Korczykowski M, Dinges DF, Detre JA. Perfusion functional MRI reveals cerebral blood flow pattern under psychological stress. Proc Natl Acad Sci USA 2005; 102: 17804-17809

47 Hermans EJ, van Marle HJ, Ossewaarde L, Henckens MJ, Qin S, van Kesteren MT, Schoots VC, Cousijn H, Rijpkema M, Oostenveld R, Fernandez $G$. Stress-related noradrenergic activity prompts large-scale neural network reconfiguration. Science 2011; 334: 1151-1153

48 Zeinstra E, Wilczak N, De Keyser J. [3H]dihydroalprenolol binding to beta adrenergic receptors in multiple sclerosis brain. Neurosci Lett 2000; 289: 75-77

49 Uhart M, Chong RY, Oswald L, Lin PI, Wand GS. Gender differences in hypothalamic-pituitary-adrenal (HPA) axis reactivity. Psychoneuroendocrinology 2006; 31: 642-652

50 Roca CA, Schmidt PJ, Deuster PA, Danaceau MA, Altemus M, Putnam K, Chrousos GP, Nieman LK, Rubinow DR. Sex-related differences in stimulated hypothalamic-pituitary-adrenal axis during induced gonadal suppression. J Clin Endocrinol Metab 2005; 90: 4224-4231

51 Weiser MJ, Handa RJ. Estrogen impairs glucocorticoid dependent negative feedback on the hypothalamic-pituitary-adrenal axis via estrogen receptor alpha within the hypothalamus. Neuroscience 2009; 159: 883-895 